
\title{
3 Research Square \\ IL-10 Promotes Glioma Cell Growth and Invasion via Upregulation of KPNA2 In vitro
}

\section{Zihao Zhang}

Nanchang University

Xiaoming Huang

Shandong University

Jie Li

Shandong University

Haitao Fan

Shandong Provincial Hospital

Fan Yang

Shandong Provincial Hospital

Rui Zhang

Shandong Provincial Hospital

Yihang Yang

Shandong Provincial Hospital

Shaobin Feng

Shandong University

Dong He

Shandong University

Wei Sun

Jiangxi Provincial People's Hospital

Tao Xin ( $\nabla$ drxintao@yeah.net)

Shandong Provincial Hospital https://orcid.org/0000-0002-8797-3002

\section{Research Article}

Keywords: Cell growth, cell invasion, glioma, IL-10, KPNA2

Posted Date: January 15th, 2019

DOl: https://doi.org/10.21203/rs.2.218/v1

License: (c) (1) This work is licensed under a Creative Commons Attribution 4.0 International License. Read Full License 


\section{Abstract}

Background: Glioma is one of the leading causes of death worldwide with high incidence, recurrence and mortality. IL-10 is a cytokine with dual function in many types of tumors. Although IL-10 is overexpressed and promotes tumor progression in human primary brain tumor, the mechanisms are largely unknown.

Methods: Glioma cells were treated with different dosages of IL-10. The cell growth was detected by CCK8, and the invasion was measured by Transwell. The relative expression of mRNAs was detected by Quantitative real-time PCR (q-PCR).

Results: We found that IL-10 treatment significantly enhanced glioma cell growth and invasion. And KPNA2 was significantly upregulated after treatment with IL-10. By performing knockdown experiments, we found that the glioma cell growth and invasion were significantly declined.

Conclusions: The results indicated that knockdown of KPNA2 significantly inhibited the growth and invasion of glioma cells. And IL-10 promotes glioma progression via upregulation of KPNA2. This study will be of important significance and provides a potential target for treatment of patients with glioma.

Keywords: Cell growth, cell invasion, glioma, IL-10, KPNA2.

\section{Background}

Glioma is the most common tumour arising from central nervous system (CNS) with an incidence of 22 per 100000 population [1], accounting for $75 \%$ of malignant primary brain tumours in adults [2]. It initiates from glial or precursor cells and the 5-year survival rates are around $10 \%$ [3]. Currently, the therapeutic strategies for glioma are surgical resection, combined with radiotherapy, chemotherapy, and/or targeted therapy according to the molecular features of the tumour for patients with newly diagnosed with glioma [4]. However, glioma remains incurable and its poor prognosis contributes to high rates of recurrence. Thus, it is essential to develop new strategies to inhibit glioma progression.

Interleukin-10 (IL-10) was first considered as a T helper 2 cytokine, which modulates the growth and differentiation of innate immune cells, endothelial cells and keratinocytes and suppresses the activation and functions of T cells [5]. Numerous kinds of cells can produce IL-10, such as Tregs, B cells, macrophages, mast cells, dendritic cells and epithelial cells in mice and human [6, 7]. IL-10 was regarded as a suppressive factor that impaired the proliferation, cytokine production and migration of effector $\mathrm{T}$ cells [8], elevated level of IL-10 inhibited cytolytic activity in transplanted tumors $[9,10]$. In the context of tumour, IL-10 is a double edged sword. IL-10 administration suppressed tumor growth and led to tumour rejection in a variety of tumours, such as melanoma, sarcomas and colorectal cancer [11-14]. Conversely, IL-10 can also promote the development of lung cancer, esophageal squamous cell carcinoma, melanoma, cervical carcinoma [15-18]. In human brain tumour, IL-10 is overexpressed in human glioma, and its overexpression increases glioma cell proliferation and motility and promotes tumourigenesis [1922]. However, the mechanisms of IL-10 on glioma development are not clearly understood. 
KPNA2 is a member of Karyopherin a family which belongs to a family of nuclear transport proteins [23]. KPNA2 is composed of a N-terminal hydrophilicimportinb-binding domain, a central hydrophobic region, and a short acidic $\mathrm{C}$-terminus and functions through regulating the subcellular translocation of cancer associated cargo proteins $[24,25]$. It was reported that KPNA2 was overexpressed in a variety of types of cancer and promoted cell growth and survival, such as breast cancer, cervical cancer, colorectal cancer and esophageal squamous cell carcinoma [26-30]. In human brain tumour, KPAN2 is overexpressed in meningiomas and infiltrative astrocytomas, and correlates significantly with the histological grade and proliferative activity [31, 32]. In human glioblastoma, Lu et al. reported that MIR517C inhibited the epithelial-to-mesenchymal (-like) transition phenotype through KPNA2-dependent disruption of TP53 nuclear translocation, indicating KPNA2 is correlated with glioblastoma development [33]. Therefore, whether IL-10-mediated inhibition of glioma cell growth and motility is dependent on KPNA2 remains unclear.

In this study, we first evaluated the effect of IL-10 on glioma cell growth and invasion. Then, the expression of KPNA2 was quantified by qPCR and knocked down using short hairpin RNA (shRNA) to demonstrate the role of KPNA2 in glioma cell growth and invasion. This study will be of important significance and provides a potential target for treatment of patients with glioma.

\section{Methods}

\section{Cell line and cell culture}

Glioma cell line U87 was purchased from American Type Culture Collection (ATCC), and cultured in RPMI1640 supplemented with $10 \%$ fetal bovine serum (FBS), $100 \mathrm{U} / \mathrm{ml}$ penicillin $\mathrm{G}$, and $100 \mu \mathrm{g} / \mathrm{ml}$ streptomycin at $37^{\circ} \mathrm{C}$ in a $5 \% \mathrm{CO}_{2}$ incubator. In all experiments, U87 cells were trypsinized at $80 \%$ confluency.

\section{Cell proliferation assay}

The CCK-8 assay was used to determine cell proliferation ability. In brief, cells were seeded at a density of $1 \times 10^{3}$ cells/well in 96 -well plates and incubated overnight at $37^{\circ} \mathrm{C}$. IL-10 was then added into the culture medium. at the indicated time points (1,2,3, and 4 days), $10 \mu$ l of CCK-8 solution was added into the culture medium, and the cells were incubated for an additional 1.5 hours at $37^{\circ} \mathrm{C}$. Then, the absorbance of each well was measured at $450 \mathrm{~nm}$ using a microplate reader. All experiments were performed in quintuplicate.

\section{Cell invasion assay}


Put $100 \mu$ diluted matrigel into upper chamber of 24-well invasion chamber and incubate at $37^{\circ} \mathrm{C}$ in a $5 \%$ CO2 atmosphere for 4-6 hours to hydrate the matrigel. Then $500 \mu \mathrm{l}$ serum-free medium was added into bottom well for 30 minutes. Cells were resuspended in $100 \mu \mathrm{l}$ serum-free media at a density of $10^{6}$ cells $/ \mathrm{ml}$, then cell suspension was added into upper chamber and $500 \mu \mathrm{l}$ completed medium was added into bottom well. After incubation overnight, cells on the upper surface of the filter membrane were scraped with cotton swabs, and those cells on the lower surface were fixed with polyoxymethylene for 30 minutes and stained with $0.1 \%$ crystal violet solution for 20 minutes. Five visual fields were randomly selected and photographed under a light microscope, and the invaded cells were counted.

\section{RNA extraction and quantitative real-time polymerase chain reaction (qPCR)}

Total RNA from U87 cells was extracted purified using RNA extraction kit according to the manufacturer's protocol. Reserve transcription was performed to generate complementary DNA (cDNA) according to the manufacturer's protocol. The mRNA level of KPNA2 was measured by qPCR using SYBR premix Ex Tap. The primers were used as follows:

$\beta$-actin forward, 5'- CCCGAGCCGTGTTTCCT -3';

$\beta$-actin reserve, 5'- GTCCCAGTTGGTGACGATGC-3';

kpna2 forward, 5'- TGATATGTCATCTTTAGCATGTGGC-3';

kpna2 reserve, 5'- GCCCACACAGCTTCCTTTTG -3';

$\beta$-actin was used as internal control. The relative mRNA expression of these genes were calculated using the $2^{-\triangle \Delta C q}$ method [34].

\section{SiRNA transfection}

The siRNAs were purchased from Ribobio company (Guangzhou, China), and the sequence of siRNA for KPNA2 is as below:

SiKPNA2-1: ATTTACAGTGCCCTGGTTG;

SIKPNA2-2: ATGAACGAATTGGCATGGT;

SIKPNA2-3: GCATGTGGCTACTTACGTA.

U87 cells were seeded in 6-well plates and cultured overnight. Next day, cells were transfected with three siRNA for KPNA2 at optimal concentration. Forty-eight hours later, cells were used for further experiments. 


\section{Statistical analysis}

The Student's t-test was used to quantify significant differences. GraphPad Prism 5 software was used for statistical analysis, Data are presented as the mean \pm SD, and a value of $P<0.05$ were considered statistically significant.

\section{Results}

\section{IL-10 promotes the proliferation of glioma cells}

Cancer progression is a complex process involving cell growth, migration, invasion, colony formation, and metastasis. To explore whether IL-10 affected glioma progression, we first detected the role of IL-10 in glioma cell growth. We cocultured glioma cell line U87 with different dosages of IL-10. After 24 hours, CCK-8 assay was performed. We found that IL-10 promoted the cell growth of U87 in a dose-dependent manner (Figure 1A). As shown in Figure 1A, IL-10 at the concentration of $50 \mathrm{ng} / \mathrm{ml}$ enhanced the proliferation of U87 cells much significantly than others (Figure 1A). Therefore, we used IL-10 at $50 \mathrm{ng} / \mathrm{ml}$ for further experiments. We also found that IL-10 significantly promoted the cell growth of U87 cells at day4 compared with negative control cells (NC) (Figure 1B). Thus, these data demonstrated that IL-10 promotes the proliferation of glioma cells.

\section{IL-10 enhances the invasion of glioma cells}

Next, we assessed the role of IL-10 in glioma cell invasion by cell invasion assay. As compared with negative control cells, IL-10 treatment remarkably increases the number of invasion cells (Figure 2A, 2B). These results demonstrated that IL-10 treatment enhanced the invasion of human glioma cells.

\section{IL-10 increases the expression of kpna2 in glioma cells}

We further explored the mechanisms by which IL-10 promoted the glioma cell proliferation and invasion. Many studied have shown that KPNA2 played a role in cell growth and invasion of many cancer cells, including human brain tumour $[26,27,29,31,32]$. Therefore, we examined the expression of kpna2 in IL10 treated U87 cells. We found that IL-10 significantly increased kpna2 mRNA levels in U87 cells compared with untreated control cells (Figure 3 ). 


\section{Knockdown of KPNA2 inhibits the proliferation of glioma cells}

To investigate the role of KPNA2 in glioma cell growth, we used siRNA to specifically silence KPNA2 in U87 cells. We first examined the knockdown efficiency of KPNA2. As shown in Figure 4A, the expression of KPNA2 was significantly inhibited in U87 cells. We found that knockdown of KPNA2 significantly inhibited the cell growth of U87 cells at day3 and day 4 compared with negative control cells (NC) (Figure 4B). Taken together, these data demonstrated that KPNA2 affected the glioma cell growth.

\section{Knockdown of KPNA2 suppressed the invasion of glioma cells}

We also assessed the effect of KPNA2 on cell invasion of U87 cells. The results showed that knockdown of KPNA2 significantly decreased the cell invasion of U87 cells. Thus, we confirmed that kpna2 contributes the invasion of glioma cells.

Taken together, we found that IL-10 promoted glioma cell progress via upregulation of KPNA2.

\section{Discussion}

In this study, we report that IL-10 promotes cell growth and invasion in glioma cells. We found that IL-10 increased the expression of KPNA2, and knockdown of KPNA2 significantly inhibited the glioma cell growth and invasion, indicating that IL-10 promotes glioma cell growth and invasion via upregulation of KPNA2.

Immunotherapy for cancer is a new and promising treatment method besides operation, radiotherapy and chemotherapy. And it has been applied to treat malignancies, such as lung cancer, melanoma, renal carcinoma and hematological malignancy [35]. IL-10 is a cytokine which plays dual function in many types of cancers [11-18]. For example, IL-10 promotes resistance to apoptosis and metastatic potential in lung cancer cell lines [15]. Overexpression of IL-10 leads to frequent event of immune evasion in esophageal squamous cell carcinoma [17]. IL-10 facilitates the progression of cervical cancer [18]. However, IL-10 is also reported to inhibit tumor development, growth, and metastasis in melanoma, colon cancer and fibrosarcoma [12, 14]. Glioma is known to secrete IL-10 [36]. Increased production of IL-10 was also reported in glioma [36, 37]. In glioma, IL-10 stimulates the tumor-associated macrophages to express B7-H1, thus suppressing the immune system [38]. On the other hand, under the influence of glioma, microglia release several classes of molecules, including IL-10, that promote glioma growth, progression and inflammatory activation [39]. To clarify the function of IL-10 in human glioma progression, we detected the glioma cell growth and invasion after treatment with IL-10. Our results reveal that IL-10 treatment promotes the glioma cell growth and invasion.

Heterogeneity is a hallmark of cancer $[40,41]$. Thus, the mechanisms of tumour cell growth, invasion, migration and metastasis in various types of tumour may be different and there are many factors to promote tumour progression in the same type of tumour. For example, long noncoding RNAs, circular 
RNAs, cytokines and migrating myeloid cells are all associated with glioma progression [19, 22, 42-44]. KPNA2 is a member of Karyopherin a family. It promotes tumour progression in many kinds of tumours, including glioma, breast cancer, cervical cancer, colorectal cancer and esophageal squamous cell carcinoma [26-29, 31-33]. KPNA2 is required for IL-1 $\beta$-induced MMP-mediated metastasis in oral cavity squamous cell carcinoma [45]. KPNA2 also enhanced TNFa-induced expression of IL-6, MMP-1, and MMP-13 and increased the P65 phosphorylation in human synovial sarcoma cells [46]. Thus, whether KPNA2 mediates IL-10 induced glioma cell growth and invasion remains unclear. In our study, we found that KPNA2 was dramatically upregulated in glioma cells after treatment with IL-10. By using shRNA, knockdown of KPNA2 significantly inhibited glioma cell growth and invasion, indicating that IL-10 maybe promote glioma cell growth dependent on KPNA2. However, further experiments will be necessary to identify the interaction of IL-10 with KPNA2.

In view of a recent study showed that KPNA2 plays a crucial role in the metabolic reprogramming of glioma cells by mediating the nuclear transportation of c-Myc and E2F1 [30], we hypothesis that IL-10 may have an important role in regulating the metabolism of glioma cells, but further experiments are needed to prove it.

\section{Conclusion}

We confirmed that IL-10 promoted glioma cell growth and invasion, and we proposed for the first time that IL-10 promoted glioma cell growth and invasion via upregulation of KPNA2. Our study provided a potential target for treatment of patients with glioma.

\section{Abbreviations}

KPNA2: Karyopherin a2

IL-10: Interleukin-10

CNS: central nervous system

q-PCR: Quantitative real-time PCR

shRNA: short hairpin RNA

\section{Declarations}

\section{Ethics approval}

Not applicable

\section{Consent for publication}


Not applicable

\section{Availability of data and materials}

The datasets used and/or analyzed during the current study are available from the corresponding author on reasonable request.

\section{Competing interests}

The authors declare that they have no competing interests.

\section{Funding}

This work was supported by Science and Technology Project of Jinan city (Grant No. 201602162), Shandong Provincial Natural Science Foundation (Grant No.ZR2014HM010), Shandong Province Science and Technology Development Program (Grant No. 2015GSF118164).

\section{Authors' contributions}

Tao Xin, Wei Sun and conceived the concept, designed the experiments. Zihao Liu and Jie Li wrote the manuscript. Zihao Liu, Xiaoming Huang, Haitao Fan, Fan Yang and Rui Zhang carried out and interpreted the experiments. Yihang Yang, Shaobin Feng, Dong He analyzed the data. All authors read and approved the final manuscript.

\section{Acknowledgements}

Not applicable

\section{References}

1. Ostrom QT, Gittleman H, Liao P, Vecchione-Koval T, Wolinsky Y, Kruchko C et al: CBTRUS Statistical Report: Primary brain and other central nervous system tumors diagnosed in the United States in 2010-2014. Neuro Oncol 2017, 19(suppl_5):v1-v88.

2. Lapointe S, Perry A, Butowski NA: Primary brain tumours in adults. Lancet 2018.

3. Stupp R, Hegi ME, Mason WP, van den Bent MJ, Taphoorn MJ, Janzer RC et al: Effects of radiotherapy with concomitant and adjuvant temozolomide versus radiotherapy alone on survival in glioblastoma in a randomised phase III study: 5-year analysis of the EORTC-NCIC trial. Lancet Oncol 2009, 10(5):459-466.

4. Jiang T, Mao Y, Ma W, Mao Q, You Y, Yang X et al: CGCG clinical practice guidelines for the management of adult diffuse gliomas. Cancer Lett 2016, 375(2):263-273.

5. Moore KW, O'Garra A, de Waal Malefyt R, Vieira P, Mosmann TR: Interleukin-10. Annu Rev Immunol 1993, 11:165-190. 
6. Dennis KL, Blatner NR, Gounari F, Khazaie K: Current status of interleukin-10 and regulatory T-cells in cancer. Curr Opin Oncol 2013, 25(6):637-645.

7. Jung HC, Eckmann L, Yang SK, Panja A, Fierer J, Morzycka-Wroblewska E et al: A distinct array of proinflammatory cytokines is expressed in human colon epithelial cells in response to bacterial invasion. J Clin Invest 1995, 95(1):55-65.

8. Moore KW, de Waal Malefyt R, Coffman RL, O'Garra A: Interleukin-10 and the interleukin-10 receptor. Annu Rev Immunol 2001, 19:683-765.

9. De Santo C, Arscott R, Booth S, Karydis I, Jones M, Asher R et al: Invariant NKT cells modulate the suppressive activity of IL-10-secreting neutrophils differentiated with serum amyloid A. Nat Immunol 2010, 11(11):1039-1046.

10. Steinbrink K, Jonuleit H, Muller G, Schuler G, Knop J, Enk AH: Interleukin-10-treated human dendritic cells induce a melanoma-antigen-specific anergy in CD8(+) T cells resulting in a failure to lyse tumor cells. Blood 1999, 93(5):1634-1642.

11. Suzuki T, Tahara H, Narula S, Moore KW, Robbins PD, Lotze MT: Viral interleukin 10 (IL-10), the human herpes virus 4 cellular IL-10 homologue, induces local anergy to allogeneic and syngeneic tumors. J Exp Med 1995, 182(2):477-486.

12. Zheng LM, Ojcius DM, Garaud F, Roth C, Maxwell E, Li Z et al: Interleukin-10 inhibits tumor metastasis through an NK cell-dependent mechanism. J Exp Med 1996, 184(2):579-584.

13. Berman RM, Suzuki T, Tahara H, Robbins PD, Narula SK, Lotze MT: Systemic administration of cellular IL-10 induces an effective, specific, and long-lived immune response against established tumors in mice. J Immunol 1996, 157(1):231-238.

14. Tanikawa T, Wilke CM, Kryczek I, Chen GY, Kao J, Nunez G et al: Interleukin-10 ablation promotes tumor development, growth, and metastasis. Cancer Res 2012, 72(2):420-429.

15. Zeng L, O'Connor C, Zhang J, Kaplan AM, Cohen DA: IL-10 promotes resistance to apoptosis and metastatic potential in lung tumor cell lines. Cytokine 2010, 49(3):294-302.

16. Vahl JM, Friedrich J, Mittler S, Trump S, Heim L, Kachler K et al: Interleukin-10-regulated tumour tolerance in non-small cell lung cancer. Br J Cancer 2017, 117(11):1644-1655.

17. Gholamin M, Moaven O, Memar B, Farshchian M, Naseh H, Malekzadeh R et al: Overexpression and interactions of interleukin-10, transforming growth factor beta, and vascular endothelial growth factor in esophageal squamous cell carcinoma. World J Surg 2009, 33(7):1439-1445.

18. Berti FCB, Pereira APL, Cebinelli GCM, Trugilo KP, Brajao de Oliveira K: The role of interleukin 10 in human papilloma virus infection and progression to cervical carcinoma. Cytokine Growth Factor Rev 2017, 34:1-13.

19. Huettner C, Czub S, Kerkau S, Roggendorf W, Tonn JC: Interleukin 10 is expressed in human gliomas in vivo and increases glioma cell proliferation and motility in vitro. Anticancer Res 1997, 17(5A):3217-3224.

20. Qiu B, Zhang D, Wang C, Tao J, Tie X, Qiao Y et al: IL-10 and TGF-beta2 are overexpressed in tumor spheres cultured from human gliomas. Mol Biol Rep 2011, 38(5):3585-3591. 
21. Qi L, Yu H, Zhang Y, Zhao D, Lv P, Zhong Y et al: IL-10 secreted by M2 macrophage promoted tumorigenesis through interaction with JAK2 in glioma. Oncotarget 2016, 7(44):71673-71685.

22. Zhen Z, Guo X, Liao R, Yang K, Ye L, You Z: Involvement of IL-10 and TGF-beta in HLA-E-mediated neuroblastoma migration and invasion. Oncotarget 2016, 7(28):44340-44349.

23. Goldfarb DS, Corbett AH, Mason DA, Harreman MT, Adam SA: Importin alpha: a multipurpose nuclear-transport receptor. Trends Cell Biol 2004, 14(9):505-514.

24. Christiansen A, Dyrskjot L: The functional role of the novel biomarker karyopherin alpha 2 (KPNA2) in cancer. Cancer Lett 2013, 331(1):18-23.

25. Wang Cl, Chien KY, Wang CL, Liu HP, Cheng CC, Chang YS et al: Quantitative proteomics reveals regulation of karyopherin subunit alpha-2 (KPNA2) and its potential novel cargo proteins in nonsmall cell lung cancer. Mol Cell Proteomics 2012, 11(11):1105-1122.

26. Dahl E, Kristiansen G, Gottlob K, Klaman I, Ebner E, Hinzmann B et al: Molecular profiling of lasermicrodissected matched tumor and normal breast tissue identifies karyopherin alpha2 as a potential novel prognostic marker in breast cancer. Clin Cancer Res 2006, 12(13):3950-3960.

27. van der Watt PJ, Maske CP, Hendricks DT, Parker MI, Denny L, Govender D et al: The Karyopherin proteins, Crm1 and Karyopherin beta1, are overexpressed in cervical cancer and are critical for cancer cell survival and proliferation. Int J Cancer 2009, 124(8):1829-1840.

28. Sakai M, Sohda M, Miyazaki T, Suzuki S, Sano A, Tanaka N et al: Significance of karyopherin-\{alpha\} 2 (KPNA2) expression in esophageal squamous cell carcinoma. Anticancer Res 2010, 30(3):851-856.

29. Yu L, Wang G, Zhang Q, Gao L, Huang R, Chen $Y$ et al: Karyopherin alpha 2 expression is a novel diagnostic and prognostic factor for colorectal cancer. Oncol Lett 2017, 13(3):1194-1200.

30. Li J, Liu Q, Liu Z, Xia Q, Zhang Z, Zhang R et al: KPNA2 promotes metabolic reprogramming in glioblastomas by regulation of c-myc. J Exp Clin Cancer Res 2018, 37(1):194.

31. Gousias K, Niehusmann P, Gielen GH, Simon M: Karyopherin a2 and chromosome region maintenance protein 1 expression in meningiomas: novel biomarkers for recurrence and malignant progression. J Neurooncol 2014, 118(2):289-296.

32. Gousias K, Becker AJ, Simon M, Niehusmann P: Nuclear karyopherin a2: a novel biomarker for infiltrative astrocytomas. J Neurooncol 2012, 109(3):545-553.

33. Lu Y, Xiao L, Liu Y, Wang H, Li H, Zhou Q et al: MIR517C inhibits autophagy and the epithelial-tomesenchymal (-like) transition phenotype in human glioblastoma through KPNA2-dependent disruption of TP53 nuclear translocation. Autophagy 2015, 11(12):2213-2232.

34. Livak KJ, Schmittgen TD: Analysis of relative gene expression data using real-time quantitative PCR and the 2(-Delta Delta C(T)) Method. Methods 2001, 25(4):402-408.

35. Rosenberg SA: Progress in human tumour immunology and immunotherapy. Nature 2001, 411(6835):380-384.

36. Hishii M, Nitta T, Ishida H, Ebato M, Kurosu A, Yagita $\mathrm{H}$ et al: Human glioma-derived interleukin-10 inhibits antitumor immune responses in vitro. Neurosurgery 1995, 37(6):1160-1166; discussion 1166- 
1167.

37. Huettner C, Paulus W, Roggendorf W: Messenger RNA expression of the immunosuppressive cytokine IL-10 in human gliomas. Am J Pathol 1995, 146(2):317-322.

38. Bloch O, Crane CA, Kaur R, Safaee M, Rutkowski MJ, Parsa AT: Gliomas promote immunosuppression through induction of B7-H1 expression in tumor-associated macrophages. Clin Cancer Res 2013, 19(12):3165-3175.

39. Li W, Graeber MB: The molecular profile of microglia under the influence of glioma. Neuro Oncol 2012, 14(8):958-978.

40. Allison KH, Sledge GW: Heterogeneity and cancer. Oncology (Williston Park) 2014, 28(9):772-778.

41. Burrell RA, McGranahan N, Bartek J, Swanton C: The causes and consequences of genetic heterogeneity in cancer evolution. Nature 2013, 501(7467):338-345.

42. Ramos AD, Attenello FJ, Lim DA: Uncovering the roles of long noncoding RNAs in neural development and glioma progression. Neurosci Lett 2016, 625:70-79.

43. Yang Y, Gao X, Zhang M, Yan S, Sun C, Xiao F et al: Novel Role of FBXW7 Circular RNA in Repressing Glioma Tumorigenesis. J Natl Cancer Inst 2018, 110(3).

44. Lim M, Xia Y, Bettegowda C, Weller M: Current state of immunotherapy for glioblastoma. Nat Rev Clin Oncol 2018, 15(7):422-442.

45. Wang $\mathrm{Cl}$, Yu CJ, Huang Y, Yi JS, Cheng HW, Kao HK et al: Association of overexpressed karyopherin alpha 2 with poor survival and its contribution to interleukin-1 beta-induced matrix metalloproteinase expression in oral cancer. Head Neck 2018, 40(8):1719-1733.

46. Liu Z, Zhang D, Sun C, Tao R, Xu X, Xu L et al: KPNA2 Contributes to the Inflammatory Processes in Synovial Tissue of Patients with Rheumatoid Arthritis and SW982 Cells. Inflammation 2015, 38(6):2224-2234.

\section{Figures}


A

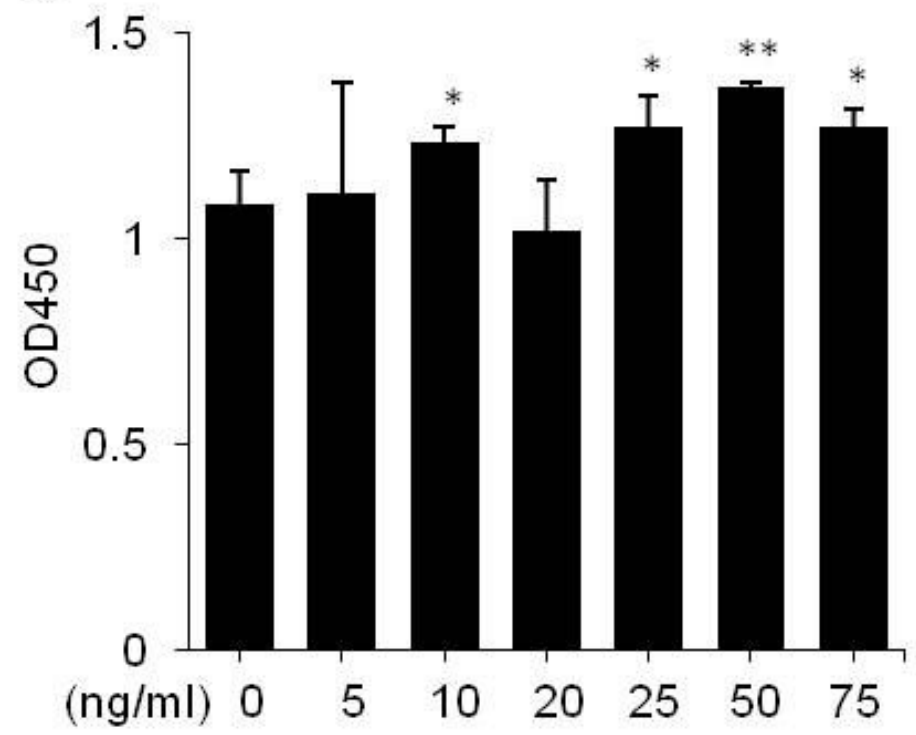

B

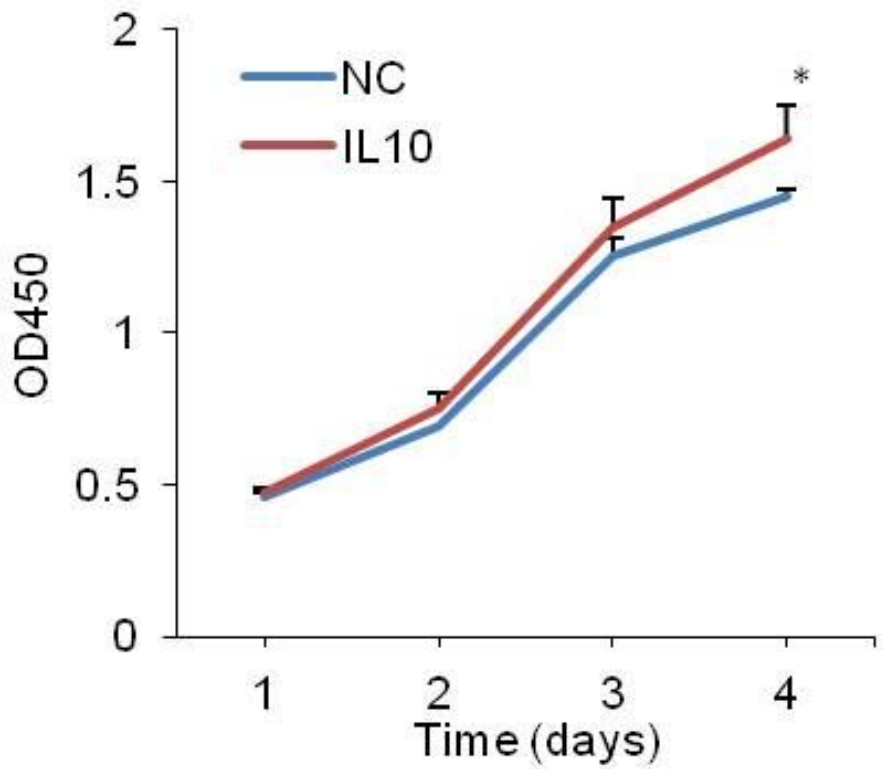

Figure 1

IL-10 enhances glioma cell proliferation - (A) U87 cells were cultured with different concentrations (5 $\mathrm{ng} / \mathrm{ml}, 10 \mathrm{ng} / \mathrm{ml}, 20 \mathrm{ng} / \mathrm{ml}, 25 \mathrm{ng} / \mathrm{ml}, 50 \mathrm{ng} / \mathrm{ml}$ and $75 \mathrm{ng} / \mathrm{ml}$ ) of IL10 for 24 hours, then CCK8 assay was performed. The results were presented as mean $\pm S D$. ${ }^{*} p<0.05,{ }^{* *} p<0.01$. (B) U87 cells were treated with or without IL-10 (50 ng/ml) for 24 hours. Cells without treatment of IL10 were used as controls (NC). CCK8 assay was performed everyday for four days. The experiment was performed in quintuplicate. Data were shown as mean $\pm S D$. * $p<0.05$.

A

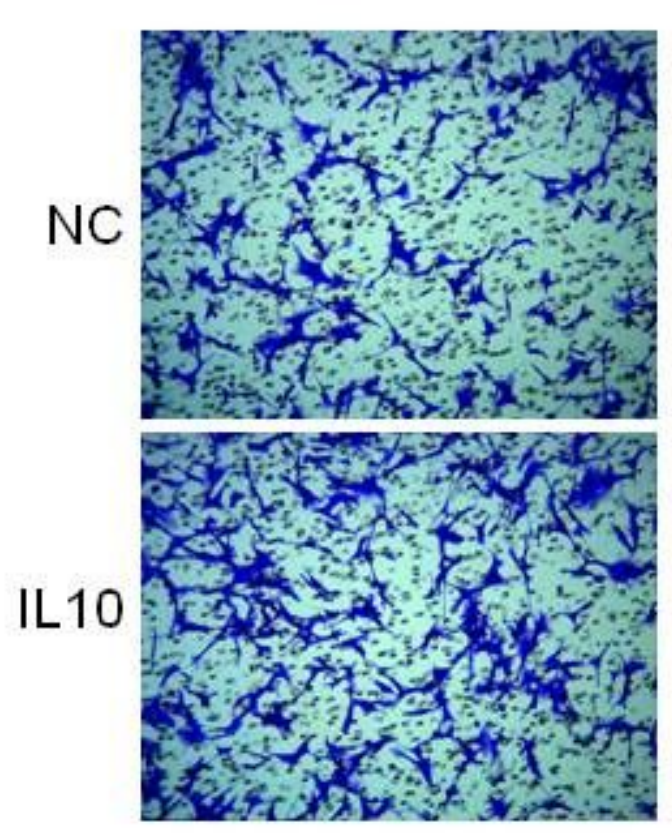

B

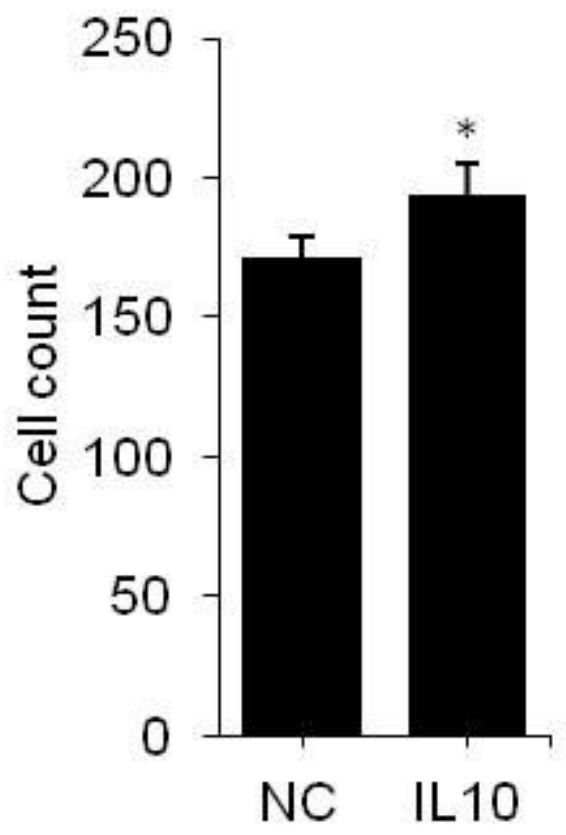

Figure 2 
IL-10 promotes glioma cell invasion - (A-B) U87 cells treated with or without (NC) IL-10 were seeded in matrigel-coated Transwell chamber overnight. Cell invasion assay was performed $(A)$ and invasion cells were counted from at least five random fields $(B)$. Data are shown as mean $\pm S D$. * $p<0.05$.

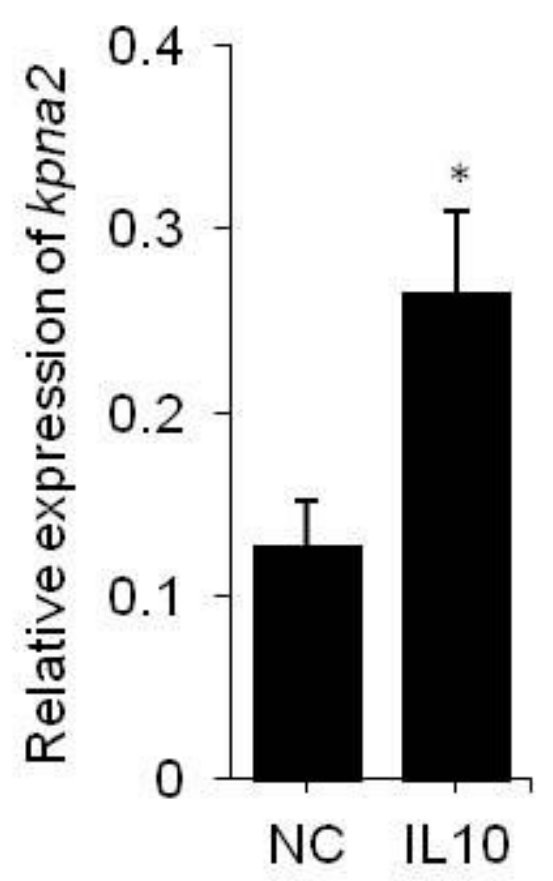

Figure 3

IL-10 increases the expression of KPNA2 in glioma cells - U87 cells were treated with or without (NC) IL-10 for 48 hours. The mRNA levels of kpna 2 was assessed by quantitative real-time PCR. Results shown are the mean \pm SD of three independent experiments. ${ }^{*} p<0.05$. 
A

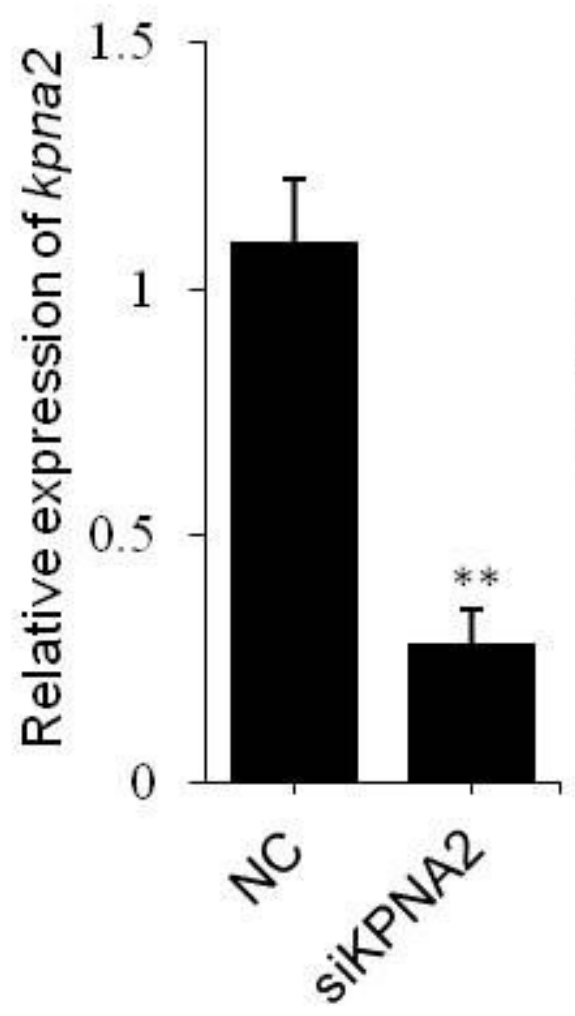

B

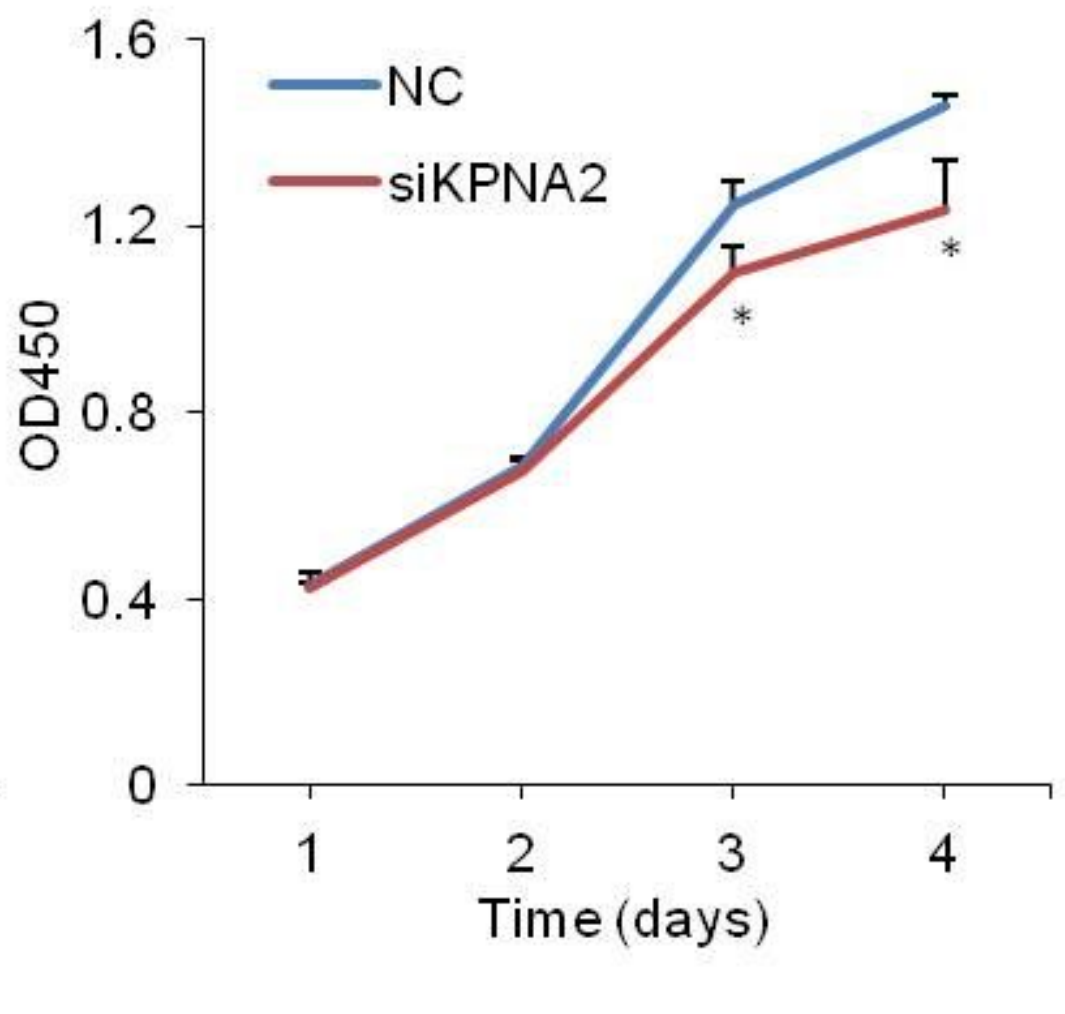

Figure 4

KPNA2 knockdown suppressed glioma cell growth - (A-B) U87 cells were infected with the negative control (NC) or KPNA2-shRNA lentivirus.(A) The mRNA levels of kpna2 was assessed by using quantitative real-time PCR. Data are shown as mean \pm SD of three independent experiments. (B) CCK8 assay assessed cell proliferation every day for 4 days. The experiment was performed in quintuplicate. Data were shown as mean $\pm S D$. ${ }^{*} p<0.05$. 


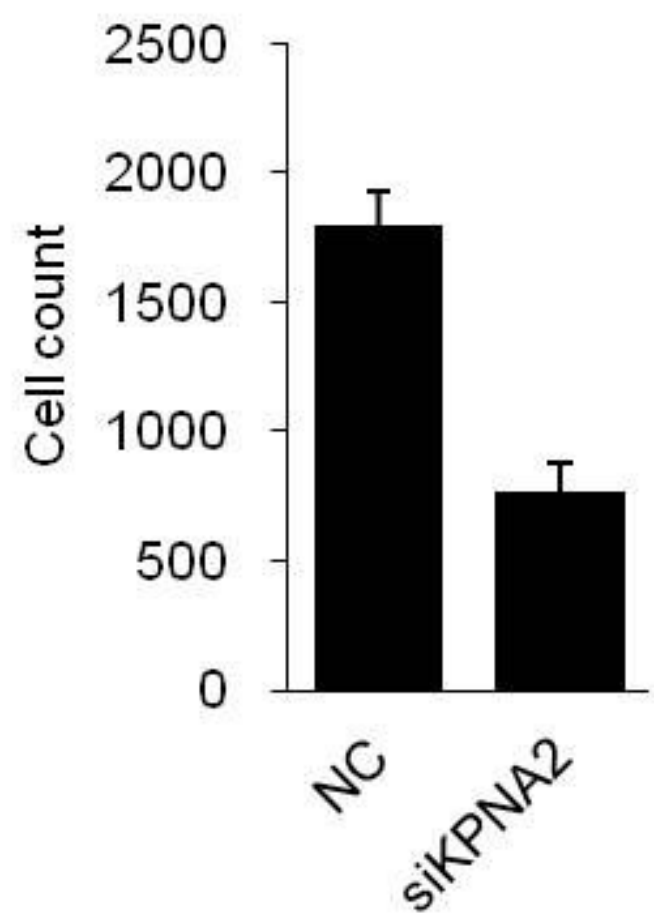

Figure 5

KPNA2 knockdown inhibited the glioma cell invasion - U87 cells infected with the control (NC) or KPNA2shRNA lentivirus were seeded in matrigel-coated Transwell chamber overnight. Then, cell invasion assay was performed. Invasion cells were counted from at least five random fields Data were presented as mean $\pm S D . * p<0.05$. 